Original research article

\title{
Endocrine responses after a single bout of moderate aerobic exercise in healthy adult humans
}

\author{
Maria Dourida ${ }^{1 *}$, Marinella Tzanela ${ }^{2}$, Athina Asimakopoulou ${ }^{2}$, Ef Botoula ${ }^{2}$, Michael Koutsilieris ${ }^{1}$, \\ Anastassios Philippou ${ }^{1}$ \\ ${ }^{1}$ National and Kapodistrian University of Athens, Medical School, Department of Physiology, Athens, Greece \\ ${ }^{2}$ Evagelismos Hospital, Department of Endocrinology-Diabetes Centre, Athens, Greece
}

\begin{abstract}
Exercise is a stress stimulus for the human organism affecting the homeostatic mechanisms of the body, depending on the type, duration, intensity and frequency of exercise. The aim of this study was to determine the effects of a moderate aerobic exercise bout on the Hypothalamo-Pituitary-Adrenal (HPA) axis acute hormonal responses in healthy adult humans. Twelve healthy male and female volunteers (age: $30.6 \pm 4.4$ years), performed a single bout of a 30 -minute aerobic exercise at $70 \%$ of $\mathrm{VO}_{2}$ max on a treadmill, following standard diet. Blood samples were collected before $\left(t_{0}\right)$, at the end of the exercise bout $\left(t_{30}\right)$, and 30 min after the completion of exercise (t60). Serum adrenocorticotropic hormone (ACTH), cortisol (COR), aldosterone (ALDO) and renin (REN) were measured. One-way ANOVA was used for statistics. ACTH and COR decreased after exercise, reaching significance $(p<0.01) 30$ min after the completion of the exercise bout. ALDO increased at the end of exercise and remained elevated 30 min after its completion. REN significantly increased at the end of exercise $(p<0.05)$ and remained elevated. The exercise regimen used in this study had beneficial effects on the stress axis, suggesting that specific exercise protocols can be characterised by mild physiological stress-inducing effects hence be prescribed for special diseased populations.
\end{abstract}

Keywords: ACTH; Aerobic exercise; Aldosterone; Cortisol; Hormonal responses; HPA axis; Renin; Stress

Abbreviations: ACTH, adrenocorticotropic hormone; ALDO, aldosterone; COR, cortisol; REN, renin; HPA axis, Hypothalamo-PituitaryAdrenal axis; RAA system, Renin-Angiotensin-Aldosterone system

\section{Introduction}

The human organism maintains stable internal environment to be able to function properly and adapt to various external stimuli and environmental conditions. Thus, during exercise, hormonal changes take place as part of homeostatic mechanisms aiming to control the physiological stress of exercise (Barrett et al., 2016).

In particular, exercise results in the activation of the endocrine component of autonomic sympathetic system and the Hypothalamo-Pituitary-Adrenal (HPA) axis aiming to maintain a dynamic equilibrium during exercise (Chrousos and Gold, 1992; Jenkins, 1999; Mastorakos and Pavlatou, 2005; Mastorakos et al., 2005; Smith and Vale, 2006). The type of exercise, its intensity and duration play a key role in these endocrine changes (Duclos et al., 2007; Viru et al., 1996; Wideman et al., 2006; 1999). Specifically, aerobic exercise seems to be a stress stimulus for the human organism, which activates responses related to the HPA axis (Smoak et al., 1991). Exercise also involves changes in the Renin-Angiotensin-Aldosterone
(RAA) system that lead to adjustments of blood pressure, to enable the organism to meet the exercise demands regarding the energy consumption and exercise-induced dehydration (Halapas et al., 2008; Powers and Howley, 2009).

The HPA axis is activated as a systemic reaction to the physiological stress of exercise once a certain threshold is reached, i.e. when exercise intensity exceeds $60-70 \%$ of $\mathrm{VO}_{2 \max }$ and happens on the first minutes of exercise commencement (Buono et al., 1987; Duclos et al., 1997; Viru, 1985). Exercise training background plays a role, as more highly trained individuals have a higher intensity threshold (Hill et al., 2008).

Adrenocorticotropic hormone (ACTH) of the HPA axis has been shown to significantly increase with prolonged moderate aerobic exercise (Bouissou et al., 1988; Duclos et al., 1997) and subsequently binds to high-affinity receptors of the adrenal cells membrane resulting in cortisol synthesis (Barrett et al., 2016). Interestingly, a gender effect has been found regarding the cortisol response to ACTH stimulation, with elderly men demonstrating a decreased responsiveness compared to women in the same age range (Lekkakou et al., 2013). COR in-

\footnotetext{
* Author for correspondence: Maria Dourida, National and Kapodistrian University of Athens, Medical School, Department of Physiology, 75 Micras Asias, Goudi-Athens, 115 27, Greece; e-mail: maria@mitarakis.gr http://doi.org/10.32725/jab.2018.004

Submitted: 2018-05-10 • Accepted: 2018-11-01 • Prepublished online: 2018-11-23

J Appl Biomed 17/1: 40-46 • EISSN 1214-0287 • ISSN 1214-021X

(C) 2018 The Authors. Published by University of South Bohemia in České Budějovice, Faculty of Health and Social Sciences.

This is an open access article under the CC BY-NC-ND license.
} 
creases immediately after the beginning of aerobic exercise of adequate intensity, as well as in prolonged exercise regardless of the exercise intensity (Kanaley et al., 2001). COR increased in healthy volunteers after endurance exercise of high intensity $\left(85 \%\right.$ of $\left.\mathrm{VO}_{2 \max }\right)$ (Kanaley et al., 2001) as well as resistance exercises (Izquierdo et al., 2009; Kraemer and Ratamess, 2005; Philippou et al., 2017; Smilios et al., 2007).

Aldosterone (ALDO) also increases as exercise intensity increases. The main triggers for ALDO secretion are REN, K ions and to a less extent, ACTH concentration. Specifically, ALDO increased during aerobic exercise in healthy participants and its maximum levels were measured at the peak exercise intensity ( $80 \%$ of $\mathrm{VO}_{2 \max }$ ), while it increased further within the following 15 min (Markou et al., 2015). Moreover, it has been established that although REN is regulated by the RAA system (Barrett et al., 2016), it can be as well secreted locally in the kidneys during exercise (Maeda et al., 2005). For instance, REN was found to increase with 30-min exercise of moderate intensity (Stephenson et al., 1989). Subsequently, the inactive angiotensin is converted to angiotensin II that stimulates the secretion of ALDO (Fasola et al., 1968; Wolf et al., 1986).

The available data in the literature regarding the relationship between exercise and stress-related hormonal responses is frequently conflicting because of the multifactorial elements that are involved in those responses and the particular characteristics of the exercise regimens used. The aim of the current study was to explore the HPA axis hormonal responses of healthy volunteers to a relatively short-term aerobic exercise regimen of moderate intensity.

\section{Materials and methods}

\section{Participants}

Twelve healthy volunteers (8 male and 4 female, age: $30.6 \pm$ 4.4 years, body mass: $77.3 \pm 12.3 \mathrm{~kg}$ and height: $1.77 \pm 0.07$ $\mathrm{m})$ participated in the study. The volunteers were asked to fill in a Medical Questionnaire and to sign the consent form. The participants were physically active but had not participated in any regular exercise program for at least 6 months before the study. These volunteers refrained from taking any nutritional supplementations or medications and were not allowed to perform any vigorous physical activities at least one week before their participation to the study. The female part of the sample was controlled for oral contraceptive use as levels of the measured hormones are affected by the use of contraceptives. They were also instructed to maintain their habitual diet, while on the day prior to the testing, they were asked to have a selected low fat diet.

\section{Experimental design}

After a short familiarization and warm-up period, the participants performed a single bout of moderate aerobic exercise on a treadmill, at the same time of the day for all subjects, i.e. between 08.30-09.30. Blood samples were collected from each individual volunteer before, immediately after and $30 \mathrm{~min}$ after the completion of the exercise. The blood sampling time points were chosen to examine the effect of the aerobic exercise regimen on the HPA axis responses.

\section{Aerobic exercise regimen}

Participants performed a 30-minute steady-state aerobic exercise at a target heart rate corresponding to each individual's $70 \%$ of $\mathrm{VO}_{2 \max }$ using the formula: \% $\mathrm{MHR}=0.6463 \times$ $\left(\% \mathrm{VO}_{2 \max }\right)+37.182$ (Swain et al., 1994). Maximum heart rate
(MHR) was estimated using the equation proposed by Jackson (2007), while for cross-validation purposes, $\mathrm{VO}_{2 \max }$ was also predicted using the Single-Stage Submaximal Treadmill Test as previously described (Ebbeling et al., 1991). Briefly, the subjects walked on a treadmill at a 5\% grade for $4 \mathrm{~min}$ at a speed of $4.8 \mathrm{~km} / \mathrm{h}(3.0 \mathrm{~m} / \mathrm{h})$. Heart rate measurement was taken just prior to stopping the test using a heart monitor and $\mathrm{VO}_{2 \max }$ was computed using the suggested formula (Ebbeling et al., 1991).

\section{Blood sampling}

Blood samples were withdrawn prior to (baseline: $t_{0}$ ), immediately after ( $\left.\mathrm{t}_{30}\right)$ and $30 \mathrm{~min}$ after the termination of exercise (after 30 min of recovery: $\mathrm{t}_{60}$ ). For the baseline blood sampling, participants were seated quietly for $30 \mathrm{~min}$ and blood samples were taken before the familiarization and warm-up period. Ten $\mathrm{ml}$ of blood were drawn and allowed to clot at room temperature for $30 \mathrm{~min}$, while samples for plasma ACTH measurements were collected into iced EDTA tubes. Then, serum or plasma was collected after centrifugation at 4,000 RPM for $10 \mathrm{~min}$ at $4{ }^{\circ} \mathrm{C}$, stored frozen in $0.2 \mathrm{ml}$ aliquots at $-80^{\circ} \mathrm{C}$ and only thawed once for analysis.

\section{Hematologic measurements}

Hemoglobin and hematocrit measurements took place for plasma correction purposes (due to possible hemoconcentration) using Hemosmart (Alis et al., 2015; Dill and Costill, 1974).

\section{Hormonal measurements}

Plasma ACTH levels were determined by a solid-phase twosite sequential chemiluminescent immunometric assay (Immulite 2000, Siemens Healthcare Diagnostic Products Ltd, Glyn Rhonwy, Llanberis, Gwynedd LL55 4EL, UK). Samples were collected into iced EDTA tubes. REN was determined by electrochemiluminescent immunoassay (Liaison Direct Renin, CLIA, DiaSorin, S.p.A. Via Crescentino, 13040 Saluggia, Italy). COR and ALDO were measured by a chemiluminescent immunometric assay (Advia Centaur XP, Siemens Healthcare Diagnostic Products Ltd, Glyn Rhonwy, Llanberis, Gwynedd LL55 4EL, UK).

\section{Statistical analysis}

One-way analysis of variance (ANOVA) with repeated measures over time was used to evaluate changes in all blood measurements (SPSS v. 24 statistical package). A non-parametric (Friedman) test was conducted where the data had violated the assumptions necessary to run the repeated measures one-way ANOVA (e.g. data not normally distributed). Where significant F ratio was found for main effect $(p<0.05)$, the means were compared using Wilcoxon signed-rank test with Bonferroni adjustment for non-parametric tests. Spearman's correlation coefficient $(r)$ was used to determine potential correlations between variables. All data are presented as mean \pm standard error of the mean (SEM). The level of significance was set at $p=0.05$.

\section{Results}

Exercise acts as a stress stimulus to the body which leads to HPA axis responses depending on the intensity and duration characteristics of the exercise. In the current study we aimed to look at the effects of a single bout of aerobic exercise on hormonal changes by employing a moderate-intensity acute 
exercise protocol. Data presented in this section refer to values after plasma correction process to account for hemoconcentration effect.

The chosen aerobic exercise regimen resulted in HPA axis responses immediately after exercise and $30 \mathrm{~min}$ after its completion. Specifically, ACTH decreased gradually reaching statistical significance after 30 min of recovery $\left(t_{60}\right)$ in comparison to baseline levels $\left(t_{0}\right)(p<0.05)$, as shown in Fig. 1.

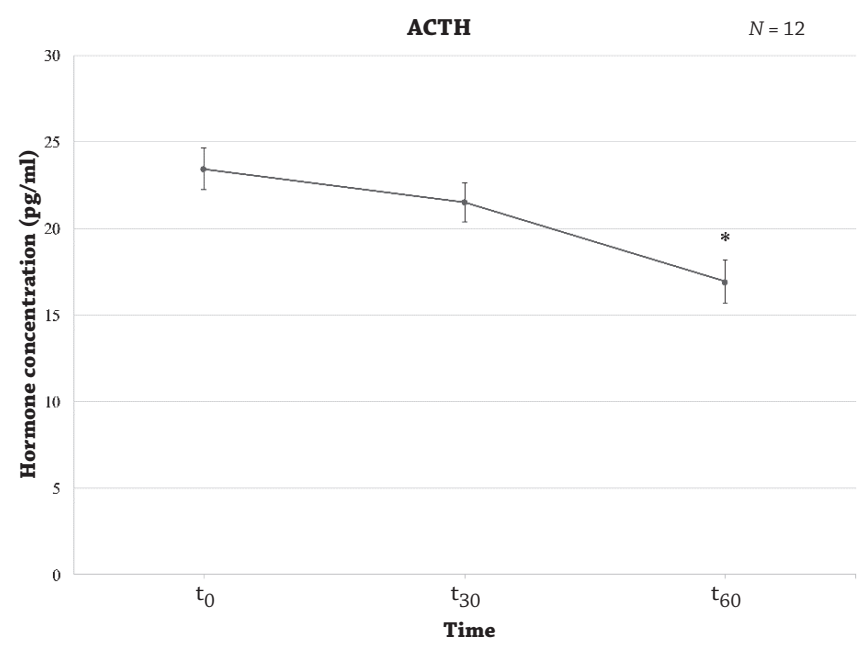

Fig. 1. ACTH response during an acute bout of aerobic exercise ACTH decreased 30 min after aerobic exercise $\left(t_{30}\right)$ on a treadmill and decreased further after $30 \mathrm{~min}$ of recovery $\left(\mathrm{t}_{60}\right)$ compared to pre-exercise concentration $\left(\mathrm{t}_{0}\right)$. Significant difference compared to $\mathrm{t}_{0}:{ }^{*} p<0.05$.

Values are presented as mean $\pm \mathrm{SEM} ; n=12$.

ACTH induces COR changes, thus we additionally explored the acute effects of the selected exercise on COR levels immediately after exercise completion ( $\left.t_{30}\right)$ and after $30 \mathrm{~min}$ of recovery ( $\mathrm{t}_{60}$ ). Similarly to ACTH responses, serum COR decreased gradually reaching statistical significance after $30 \mathrm{~min}$ of recovery $\left(\mathrm{t}_{60}, p<0.001\right)$ compared to $\mathrm{t}_{0}$, as shown in Fig. 2.

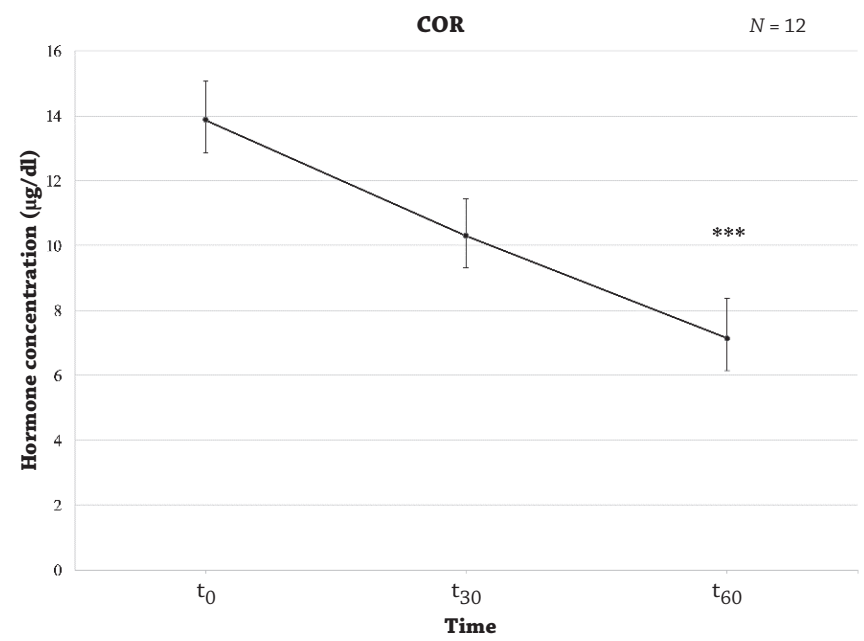

Fig. 2. Serum COR response during an acute bout of aerobic exercise Serum COR decreased 30 min after aerobic exercise $\left(t_{30}\right)$ on a treadmill and decreased further after 30 min of recovery $\left(t_{60}\right)$ compared to preexercise concentration $\left(\mathrm{t}_{0}\right)$. Significant difference compared to $\mathrm{t}_{0}$ : ${ }^{* * *} p<0.001$. Values are presented as mean $\pm \mathrm{SEM} ; n=12$.
ALDO levels increased immediately after the termination of exercise $\left(t_{30}\right)$ and remained elevated after 30 min of recovery $\left(t_{60}\right)$, however without reaching significant difference $p=$ 0.327, as shown in Fig. 3.

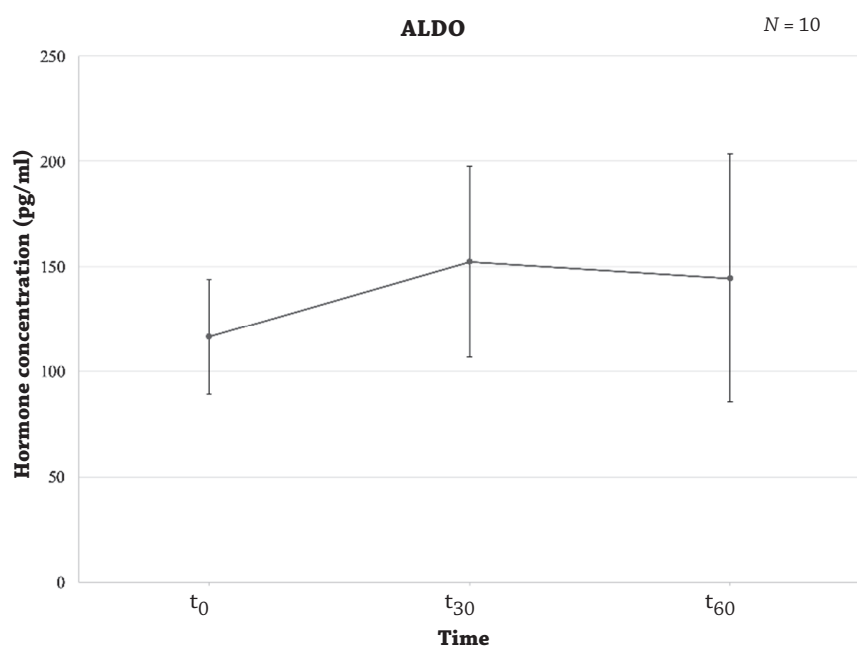

Fig. 3. ALDO response during an acute bout of aerobic exercise ALDO increased 30 min after aerobic exercise $\left(t_{30}\right)$ on a treadmill and decreased 30 min of recovery $\left(\mathrm{t}_{60}\right)$ compared to pre-exercise concentration $\left(\mathrm{t}_{0}\right)$. Values are presented as mean $\pm \mathrm{SEM} ; n=10$.

As to REN, it increased significantly immediately after the termination of exercise ( $\left.\mathrm{t}_{30}, p<0.05\right)$ in comparison to baseline levels and remained elevated after $30 \mathrm{~min}$ of recovery $\left(\mathrm{t}_{60}\right)$, as shown in Fig. 4. Table 1 presents raw values for the four studied hormones (ACTH, COR, ALDO and REN). Moreover, we explored the interaction between selected hormones with correlation analyses, which did not reveal any significant associations between the hormonal responses at any time point.

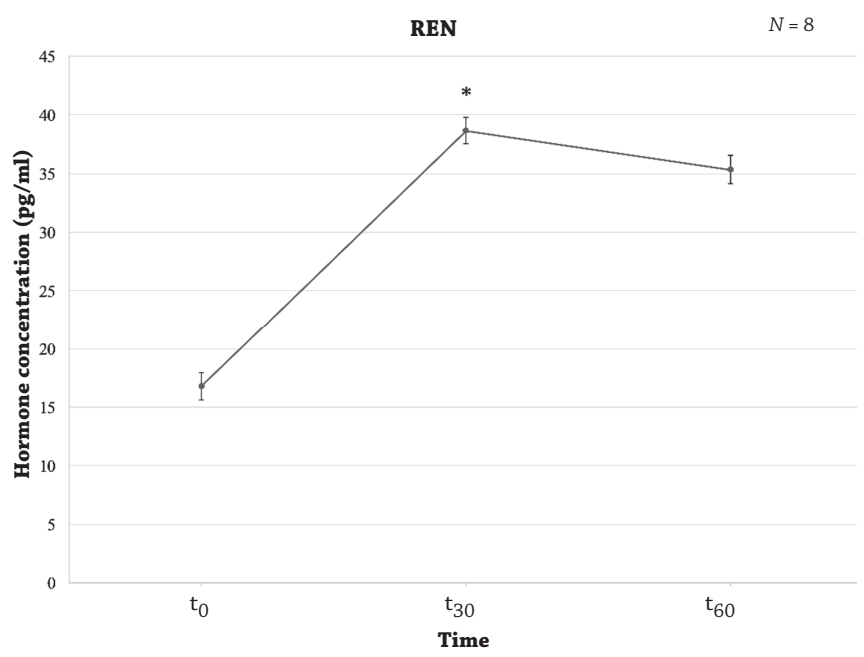

Fig. 4. REN response during an acute bout of aerobic exercise REN increased 30 min after aerobic exercise $\left(t_{30}\right)$ on a treadmill and remained increased 30 min of recovery $\left(\mathrm{t}_{60}\right)$ compared to pre-exercise concentration $\left(\mathrm{t}_{0}\right)$. Significant difference compared to $\mathrm{t}_{0}:{ }^{*} p<0.05$. Values are presented as mean $\pm \mathrm{SEM} ; n=8$. 
We explored possible differential responses between males and females within our sample. In relation to sex categorization, it was found that males presented similar pattern of alterations compared to females for COR, which decreased gradually and reached significant difference after $30 \mathrm{~min}$ of recovery ( $\left.\mathrm{t}_{60}, p<0.01\right)$, for both groups, as shown in Table 1 . ACTH decreased gradually ( $\left.\mathrm{t}_{30}\right)$ and reached significant difference at $\mathrm{t}_{60}$, compared to baseline $\left(\mathrm{t}_{0}, p<0.01\right)$ for the male group, whereas in the female group $\mathrm{ACTH}$ was found to remain stable at the end of exercise ( $\left.\mathrm{t}_{30}\right)$ and after $30 \mathrm{~min}$ of recovery $\left(t_{60}\right)$, compared to baseline $\left(t_{0}\right)$, as shown in Table 1 . In regards with ALDO, both males and females showed increased levels after the completion of exercise ( $\left.t_{30}\right)$, compared to baseline $\left(\mathrm{t}_{0}\right)$. For females, ALDO increased gradually $\left(\mathrm{t}_{30}\right)$ reaching significant difference after $30 \mathrm{~min}$ of recovery ( $\left.\mathrm{t}_{60}, p<0.05\right)$, compared to baseline ( $\left.t_{0}\right)$, as shown in Table 1 . REN increased after exercise completion ( $\left.t_{30}\right)$ in both males and females, reaching statistical significance only in the male group ( $\left.t_{30}, p<0.001\right)$, compared to baseline ( $\left.t_{0}\right)$. Interestingly, in males REN levels exhibited a significant decrease after 30 min of recovery ( $\left.t_{60}\right)$, compared to baseline $\left(\mathrm{t}_{0}\right)$, without reaching pre-exercise levels. In the female group, REN remained elevated after 30 min of recovery $\left(\mathrm{t}_{60}\right)$ in comparison to baseline levels $\left(\mathrm{t}_{0}\right)$, as shown in Table 1.

Table 1. Means and standard errors for the measured hormones after a single bout of moderate aerobic exercise in healthy adult humans, for all participants and female/male grouping

\begin{tabular}{|c|c|c|c|c|c|}
\hline \multirow[t]{4}{*}{ All } & Time points & ACTH $(\mathrm{pg} / \mathrm{ml})$ & $\operatorname{COR}(\mu \mathrm{g} / \mathrm{dl})$ & $\operatorname{ALDO}(\mathrm{pg} / \mathrm{ml})$ & $\mathrm{REN}(\mathrm{pg} / \mathrm{ml})$ \\
\hline & $\mathrm{t}_{0}$ & $23.4 \pm 2.3$ & $13.9 \pm 1.2$ & $116.4 \pm 27.1$ & $16.8 \pm 4.0$ \\
\hline & $t_{30}$ & $21.5 \pm 2.4$ & $10.3 \pm 1.1$ & $152.2 \pm 45.5$ & $38.6 \pm 8.0^{\mathrm{a}}$ \\
\hline & $\mathrm{t}_{60}$ & $16.9 \pm 1.6^{\mathrm{a}}$ & $7.1 \pm 1.2^{c}$ & $144.4 \pm 59.0$ & $35.3 \pm 8.2$ \\
\hline \multirow[t]{3}{*}{ Females } & $\mathrm{t}_{0}$ & $20.0 \pm 10.0$ & $15.1 \pm 7.6$ & $64.7 \pm 32.4$ & $8.9 \pm 4.4$ \\
\hline & $t_{30}$ & $22.3 \pm 11.1$ & $9.3 \pm 4.7$ & $130.2 \pm 65.1$ & $18.3 \pm 9.2$ \\
\hline & $\mathrm{t}_{60}$ & $19.5 \pm 9.8$ & $7.0 \pm 3.5^{\mathrm{b}}$ & $230.7 \pm 115.3^{a}$ & $23.4 \pm 11.7$ \\
\hline \multirow[t]{3}{*}{ Males } & $\mathrm{t}_{0}$ & $25.2 \pm 9.0$ & $13.2 \pm 4.7$ & $138.6 \pm 49.0$ & $24.7 \pm 8.7$ \\
\hline & $t_{30}$ & $20.0 \pm 7.1$ & $10.8 \pm 3.8$ & $167.0 \pm 59.0$ & $50.8 \pm 18.0^{c}$ \\
\hline & $\mathrm{t}_{60}$ & $15.7 \pm 5.5^{\mathrm{a}}$ & $7.2 \pm 2.5^{b}$ & $110.0 \pm 38.9$ & $37.4 \pm 13.2^{\mathrm{a}}$ \\
\hline
\end{tabular}

ACTH, adrenocorticotropic hormone; ALDO, aldosterone; COR, cortisol; REN, renin.

The presented symbols show the time points. Symbol to represents the pre-exercise time point, $\mathrm{t}_{30}$ represents 30 min of exercise

(completion of exercise) and $t_{60}$ represents 30 min post-exercise.

Significant difference compared to $\mathrm{t}_{0}:{ }^{\mathrm{a}} p<0.05 ;{ }^{\mathrm{b}} p<0.01 ;{ }^{\mathrm{c}} p<0.001$.

Values are presented as mean \pm SEM.

When post-exercise responses were analysed as percent changes of the baseline levels, a similar pattern with the original values alterations was observed, in regards with ACTH and COR (data shown in Table 1). Correlation analyses did not reveal any significant associations between the hormonal responses at any time point (data not shown). In addition, ACTH changes exhibited significant further decrease after $30 \mathrm{~min}$ of recovery $\left(\mathrm{t}_{60}, p<0.01\right)$, compared to responses at the end of exercise $\left(t_{30}\right)$, as shown in Table 2 . ALDO presented significant increase after exercise completion ( $\left.\mathrm{t}_{30}, p<0.001\right)$ and significantly increased further after 30 min of recovery $\left(\mathrm{t}_{60}\right.$, $p<0.001)$, compared to baseline $\left(\mathrm{t}_{0}\right)$. REN increased significantly after exercise completion $\left(t_{30}, p<0.01\right)$ and remained increased after 30 min of recovery ( $\left.\mathrm{t}_{60}, p<0.05\right)$, compared to baseline $\left(\mathrm{t}_{0}\right)$, as shown in Table 2 .

\section{Discussion}

In the current study we examined the effects of a single bout of aerobic exercise on the acute hormonal responses associated with physiological stress in healthy male and female volunteers. The hormones of interest were ACTH, cortisol (COR), aldosterone (ALDO) and renin (REN) in an attempt to determine alterations in the stress response system of HPA axis to a moderate-intensity exercise regimen. Interestingly, it was found that ACTH and COR significantly decreased while ALDO increased and REN significantly increased and remained elevated, after the completion of the specific exercise regimen.
Table 2. Percent changes of the measured hormones after a single bout of moderate aerobic exercise in healthy adult humans compared to $t_{0}$

\begin{tabular}{lcccc}
\hline \multirow{2}{*}{$\begin{array}{l}\text { Time } \\
\text { points }\end{array}$} & \multicolumn{4}{c}{ Hormones } \\
\cline { 2 - 5 } & ACTH & COR & ALDO & REN \\
\hline $\mathrm{t}_{0}$ & $100 \pm 0.0$ & $100 \pm 0.0$ & $100 \pm 0.0$ & $100 \pm 0.0$ \\
$\mathrm{t}_{30}$ & $91.8 \pm 33.1$ & $74.3 \pm 29.8$ & $177.6 \pm 34.6^{\mathrm{c}}$ & $240.2 \pm 86.0^{\mathrm{b}}$ \\
$\mathrm{t}_{60}$ & $72.3 \pm 21.5^{\mathrm{a}, \mathrm{d}}$ & $51.5 \pm 32.4^{\mathrm{c}}$ & $225.7 \pm 64.0^{\mathrm{c}}$ & $237.8 \pm 76.0^{\mathrm{a}}$ \\
\hline
\end{tabular}

ACTH, adrenocorticotropic hormone; ALDO, aldosterone; COR, cortisol; REN, renin.

The presented symbols show the time points. Symbol to represents the pre-exercise time point, $t_{30}$ represents 30 min of exercise (completion of exercise) and $\mathrm{t}_{60}$ represents $30 \mathrm{~min}$ post-exercise.

Significant difference compared to to: ${ }^{\mathrm{a}} p<0.05 ; \mathrm{b} p<0.01 ;{ }^{c} p<0.001$. Significant difference compared to $\mathrm{t}_{30}$ : $\mathrm{d}_{p}<0.01$.

Values are presented as mean \pm SEM.

The decreases in ACTH and COR following aerobic exercise observed in this study are in accordance with the data presented by Kraemer et al. (1989) who studied the effects of a 30-min aerobic exercise on ACTH and COR responses. Interestingly, Luger et al. (1987) found that ACTH and COR did not change after 20 min of aerobic exercise at $50 \%$ of $\mathrm{VO}_{2 \max }$, however when they tested those hormones at the higher intensity of $70 \%$ of $\mathrm{VO}_{2 \max }$ they found that the HPA axis was activated, leading to non-significant increases of ACTH and COR. Simi- 
larly, Farrell et al. (1983) reported that ACTH increased with exercise and that a correlation between ACTH and COR was depended on the intensity of exercise. Specifically, they found that both HPA axis hormones increased non-significantly following $20 \mathrm{~min}$ of aerobic exercise at $65 \%$ of $\mathrm{VO}_{2 \max }$. These findings are in contrast with the significant decreases of both hormones post-exercise which were found in the current study. It is possible that ACTH and COR did not show a decrease in the aforementioned studies, because of the lower duration of exercise bout used, suggesting that the acute decrease of these hormones may not be exercise intensity only but also exercise duration-regulated.

In this notion, Duclos et al. (1997) showed that COR remained unchanged after 20 min aerobic exercise at $80 \% \mathrm{HR}_{\max }$ $\left(70 \%\right.$ of $\left.\mathrm{VO}_{2 \max }\right)$ as well as after $120 \mathrm{~min}$ at the intensity of $50 \% \mathrm{HR}_{\max }\left(40 \%\right.$ of $\left.\mathrm{VO}_{2 \max }\right)$. In addition, Jacks et al. (2002) demonstrated that aerobic exercise with duration less than $40 \mathrm{~min}$ did not elicit significant responses regardless of intensity level, while exercise induced COR increase when its intensity was high (70-80\% of $\mathrm{VO}_{2 \text { max }}$ ). In another study, COR was found to decrease in healthy women who participated in aerobic exercise at $60 \%$ of $\mathrm{VO}_{2 \max }$ on cycle ergometer, when exercise took place in the afternoon as opposed to the morning in which case increased (Stephenson et al., 1989). In addition, Hill et al. (2008) showed that cycling aerobic exercise at $40 \%$ of $\mathrm{VO}_{2 \max }$ resulted in decreased ACTH and COR levels while exercise at $80 \%$ of $\mathrm{VO}_{2 \max }$ induced increases of these hormones. Similarly, both COR and ACTH circulating levels increased after 10 min of exercise at $90 \%$ of $\mathrm{VO}_{2 \max }$ (Deuster et al., 2000). Interestingly, ACTH seems to significantly increase with prolonged moderate aerobic exercise, such as $120 \mathrm{~min}$ at $80 \%$ of $\mathrm{VO}_{2 \max }$ (Duclos et al., 1997), or $60 \mathrm{~min}$ at $65 \%$ of $\mathrm{VO}_{2 \max }$ (Bouissou et al., 1988). It was also suggested that COR responses take place within the first minutes of the stimulus through the HPA axis and a rapid change (increase) of COR may not be mediated via the action of ACTH (Viru, 1985). The COR decline, which applies in the current study, may indicate a high metabolic clearance rate, as discussed by Hill et al. (2008). It has been suggested that COR decreases as the rate of its removal from plasma increases at a specific intensity of aerobic exercise defined at the critical point of around $60 \%$ of $\mathrm{VO}_{2 \max }$ (Davies and Few, 1973). A late onset increase of COR cannot be the reason for the discrepancy in findings, as the current study employed an aerobic protocol with the same or longer duration in comparison with the above reviewed studies. However, the conflicting findings may be a result of the different time of testing. Luger et al. (1987) conducted their testing in the evening as opposed to the morning testing of the current study. ACTH and COR secretion is pulsatile, modulated by circadian rhythm (Veldhuis et al., 1989). These hormones exhibit high circulating levels in the morning with a gradual decrease throughout the day, becoming low in the evening.

In this context, Kanaley et al. (2001) studied the relationship between exercise and COR release, investigating the effect of time of the day, when exercise takes place, on the COR secretion. Specifically, they measured serum cortisol levels after an acute bout of a 30-min aerobic exercise at high intensity $(85 \%$ of $\mathrm{VO}_{2 \text { max }}$ ), in ten healthy males and found that serum COR release was dependent on the time of the day when exercise was taking place. COR release was higher in the morning as opposed to the afternoon and evening therefore the relative increase is expected to be higher in the evening (Kanaley et al., 2001).

Another finding of the present study was that ALDO increased at the end of the 30-min exercise and remained el- evated after $30 \mathrm{~min}$ of recovery, or showed further increase when percent changes were calculated. Stephenson et al. (1989) studied the effects of aerobic exercise on ALDO levels in healthy females and found that circulating ALDO increased during exercise while the time of the day did not influence the hormone release. In the current study, the female sample group was limited in size hence the effects of exercise on female population cannot be generalized. In addition, Buono and Yaeger (1991) showed that ALDO significantly increased by exercise at the intensity of $60 \%$ of $\mathrm{VO}_{2 \text { max }}$. This increase preceded that of COR. Freund et al. (1991) suggested that exercise at $40 \%$ of $\mathrm{VO}_{2 \max }$ or above was an adequate stimulus to activate ALDO secretion in healthy volunteers. Patlar (2009) studied the effect of a thirty-minute treadmill submaximal acute exercise ( $70 \%$ of $\mathrm{VO}_{2 \max }$ ) on ALDO and REN secretion and they found that they increased significantly after exercise and remained elevated for two hours post exercise. This is in consistency with the findings of Bocqueraz et al. (2004) who performed a cycling protocol of moderate intensity. Yamauchi et al. (1998) suggested that ALDO increased after high-intensity aerobic exercise as a result of the increase of plasma hydrogen ion concentrations, as opposed to REN release. The specific authors suggested that ALDO increased with exercise independently of the HPA axis and the RAA system. Nevertheless, increased REN activity was suggested to be a stimulus for ALDO release during exercise (Stephenson et al., 1989), which is consistent with our findings.

Geyssant et al. (1981) found that both ALDO and REN circulating levels increased after one hour of aerobic exercise at $87 \%$ of $\mathrm{VO}_{2 \max }$. In addition, Wolf et al. (1986) found that cycling exercise at $40-50 \%$ of $\mathrm{VO}_{2 \max }$ raised blood levels of ALDO and REN and similarly, Stephenson et al. (1989) reported that ALDO and REN increased immediately after 30 min of cycling at $60 \%$ of $\mathrm{VO}_{2 \max }$. Increased REN release has also been reported after prolonged exercise (Sundsfjord et al., 1975). Exercise-induced REN increases are thought to reflect the needs for increased vasoconstriction during exercise, as the blood volume decreased in circulation (Barrett et al., 2016). Exercise-induced vasoconstriction and decrease in blood flow in the kidneys enable increased blood flow in the muscles during exercise so as to reach equilibrium of electrolytes level, water balance and blood pressure (Maeda et al., 2005). Overall, the findings of our study are in accordance with the results of the above studies, suggesting that the aerobic exercise regimen used in the present study constitutes not only a mild physiological stress-inducing stimulus but also an adequate one for triggering efficient homeostatic reactions of the exercising body. This could have important clinical implications associated with exercise prescription for specific diseased populations that need to avoid excess physiological stress.

\section{Conclusions}

The main findings of the study were that ACTH and COR decreased while ALDO and REN increased following the specific aerobic exercise bout. These findings indicate that such aerobic exercise protocols do not constitute a stressful stimulus for the human body therefore exercise benefits are gained without the potential side effects of exercise. The exercise-induced decreases in ACTH and COR levels make the specific exercise regimen optional for sedentary individuals as well as diseased populations who need to exercise without increasing physiological stress. It would be of particular interest to determine the optimum exercise protocol that offers the exercise benefits 
without its stressful effects. Hence, more research is required that will determine specific exercise protocols which can be recommended and prescribed for specific diseased populations and various age groups.

\section{Ethical approval}

All the volunteers provided written informed consent to participate in this study, which has been approved by the University's Ethics Committee (National and Kapodistrian University of Athens), while all experimental procedures conformed to the Declaration of Helsinki.

\section{Conflict of interests}

The authors have no conflict of interests to declare.

\section{Acknowledgements}

The authors are grateful to the study participants for their invaluable contribution to this research project.

\section{References}

Alis R, Sanchis-Gomar F, Primo-Carrau C, Lozano-Calve S, Dipalo M, Aloe R, et al. (2015). Hemoconcentration induced by exercise: Revisiting the Dill and Costill Equation. Scand J Med Sci Sports 25: 630-637. DOI: 10.1111/sms.12393.

Barrett KE, Barman SM, Boitano S, Brooks HL (2016). Ganong's Review of Medical Physiology, 25th edition. McGraw Hill Education.

Bocqueraz O, Koulmann N, Guigas B, Jimenez C, Melin B (2004). Fluid-regulatory hormone responses during cycling exercise in acute hypobaric hypoxia. Scand J Med Sci Sports 36: 1730-1736. DOI: 10.1249/01.MSS.0000142368.56816.E5

Bouissou P, Fiet J, Guezennec CY, Pesquies PC (1988). Plasma adrenocorticotrophin and cortisol responses to acute hypoxia at rest and during exercise. Eur J Appl Physiol 57: 110-113. DOI: 10.1007/BF00691248.

Buono MJ, Yeager JE (1991). Increases in aldosterone precede those of cortisol during graded exercise. J Sports Med Phys Fitness 31: 48-51.

Buono MJ, Yeager JE, Sucec AA (1987). Effect of aerobic training on the plasma ACTH response to exercise. J Appl Physiol 63: 2499-2501. DOI: 10.1152/jappl.1987.63.6.2499.

Chrousos GP, Gold PW (1992). The concepts of stress system disorders: overview of behavioral and physical homeostasis. JAMA 267: 1244-1252. DOI: 10.1001/jama.1992.03480090092034.

Davies CTM, Few JD (1973). Effects of exercise on adrenocortical function. J Appl Physiol 35: 887-891. DOI: 10.1152/ jappl.1973.35.6.887.

Deuster PA, Petrides JS, Singh A, Chrousos GP, Poth M (2000). Endocrine Response to High-Intensity Exercise: Dose-Dependent Effects of Dexamethasone. J Clin Endocrinol Metab 85: 10661073. DOI: $10.1210 /$ jcem.85.3.6444.

Dill DB, Costill DL (1974). Calculation of percentage changes in volume of blood, plasma, and red cells in dehydration. J Appl Physiol 37: 247-248. DOI: 10.1152/jappl.1974.37.2.247.

Duclos M, Corcuff JB, Rashedi M, Fougere V, Manier G (1997). Trained versus untrained men: different immediate post-exercise responses of pituitary-adrenal axis. Eur J Appl Physiol 75: 343-350. DOI: 10.1007/s004210050170.

Duclos M, Guinot M, Le Bouc Y (2007). Cortisol and GH: odd and controversial ideas. Appl Physiol Nutr Metab 32: 895-903. DOI: 10.1139/H07-064.

Ebbeling CB, Ward A, Puleo EM, Widrick J, Rippe JM (1991). Development of a single-stage submaximal treadmill walking test. Med Sci Sports Exerc 23: 966-973. DOI: 10.1249/00005768199108000-00017.
Farrell PA, Garthwaite TL, Gustafson AB (1983). Plasma adrenocorticotropin and cortisol responses to submaximal and exhaustive exercise. J Appl Physiol Respir Environ Exerc Physiol 55: 1441-1444. DOI: 10.1152/jappl.1983.55.5.1441.

Fasola AF, Martz BL, Helmer OM (1968). Plasma renin activity during supine exercise in offspring of hypertensive parents. J Appl Physiol 25: 410-415. DOI: 10.1152/jappl.1968.25.4.410.

Freund BJ, Shizuru EM, Hashiro GM, Claybaugh JR (1991). Hormonal, electrolyte, and renal responses to exercise are intensity dependent. J Appl Physiol 70: 900-906. DOI: 10.1152/ jappl.1991.70.2.900.

Geyssant A, Geelen G, Denis C, Allevard AM, Vincent M, Jarsaillon M, et al. (1981). Plasma Vasopressin, renin activity, and aldosterone: effect of exercise and training. Eur J Appl Physiol Occup Physiol 46: 21-30. DOI: 10.1007/BF00422171.

Halapas A, Papalois A, Stauropoulou A, Philippou A, Pissimissis N, Chatzigeorgiou A, et al. (2008). In vivo models for heart failure research. In Vivo 22: 767-780.

Hill EE, Zack E, Battaglini C, Viru M, Viru A, Hackney AC (2008). Exercise and circulating cortisol levels: The intensity threshold effect. J Endocrinol Invest 31: 587-591. DOI: 10.1007/ BF03345606.

Izquierdo M, Ibañez J, Calbet JAL, Navarro-Amezqueta I, GonzálezIzal M, Idoate F, et al. (2009). Cytokine and hormone responses to resistance training. Eur J Appl Physiol 107: 397. DOI: 10.1007/ s00421-009-1139-x.

Jacks DE, Sowash J, Anning J, McLoughlin T, Andres J (2002). Effect of Exercise at Three Exercise Intensities on Salivary Cortisol. J Strength Con Res 16: 286-289. DOI: 10.1519/00124278200205000-00018.

Jackson AS (2007). Estimating Maximum Heart Rate From Age: Is It a Linear Relationship? Med Sci Sports Exerc 39: 822-829. DOI: $10.1249 / \mathrm{mss} .0 \mathrm{~b} 013 \mathrm{e} 318054 \mathrm{~d} 3 \mathrm{ca}$.

Jenkins PJ (1999). Growth hormone and exercise. Clin Endocrinol (Oxf) 50: 683-689. DOI: 10.1046/j.1365-2265.1999.00784.x.

Kanaley JA, Weltman JY, Pieper KA, Weltman A, Hartman ML (2001). Cortisol and growth hormone responses to exercise at different times of day. J Clin Endocrinol Metab 86: 2881-2889. DOI: 10.1210/jcem.86.6.7566.

Kraemer RR, Blair S, Kraemer GR, Castracane VD (1989). Effects of treadmill running on plasma beta-endorphin, corticotropin, and cortisol levels in male and female $10 \mathrm{~K}$ runners. Eur J Appl Physiol Occup Physiol 58: 845-851. DOI: 10.1007BF02332217.

Kraemer WJ, Ratamess NA (2005). Hormonal responses and adaptations to resistance exercise and training. Sports Med 35: 339-361. DOI: 10.2165/00007256-200535040-00004.

Lekkakou L, Tzanela M, Lymberi M, Consoulas C, Tsagarakis S, Koutsilieris M (2013). Effects of gender and age on hypothalamicpituitary-adrenal reactivity after pharmacological challenge with low-dose 1-lg ACTH test: a prospective study in healthy adults. Clin Endocrinol (Oxf) 1-6. DOI: 10.1111/cen.12198.

Luger A, Deuster PA, Kyle SB, Gallucci WT, Montgomery LC, Gold PW, et al. (1987). Acute hypothalamic-pituitary-adrenal responses to the stress of treadmill exercise. N Engl J Med. 316: 1309-1315. DOI: 10.1056/NEJM198705213162105.

Maeda S, Iemitsu M, Jesmin S, Miyauchi T (2005). Acute exercise causes an enhancement of tissue renin-angiotensin system in the kidney in rats. Acta Physiol Scand 185: 79-86. DOI: 10.1111/j.1365-201X.2005.01459.x.

Markou A, Sertedaki A, Kaltsas G, Androulakis II, Marakaki C, Pappa T et al. (2015). Stress-induced aldosterone hyper-secretion in a substantial subset of patients with essential hypertension. J Clin Endocrinol Metab 100, 2857-2864. DOI: 10.1210/jc.20151268.

Mastorakos G, Pavlatou M (2005). Exercise as a stress model and the interplay between the hypothalamus-pituitary-adrenal and the hypothalamus-pituitary-thyroid axes. Horm Metab Res 37: 577-584. DOI: 10.1055/s-2005-870426.

Mastorakos G, Pavlatou M, Diamanti-Kandarakis E, Chrousos GP (2005). Exercise and the stress system. Hormones (Athens) 4: $73-89$. 
Patlar S (2009). Effect of acute submaximal exercise on plasma renin and aldosterone levels in sedentary people. Asian J Chem 21: 6957-6961.

Philippou A, Maridaki M, Tenta R, Koutsilieris M (2017). Hormonal responses following eccentric exercise in humans. Hormones (Athens) 16: 405-413. DOI: 10.14310/horm.2002.1761.

Powers KS, Howley ET (2009). Exercise Physiology: Theory and Application to Fitness and Performance. New York: McGraw-Hill Higher Education.

Smilios I, Pilianidis T, Karamouzis M, Parlavantzas A, Tokmakidis SP (2007). Hormonal responses after a strength endurance resistance exercise protocol in young and elderly males. Int J Sports Med 28: 401-406. DOI: 10.1055/s-2006-924366.

Smith SM, Vale WW (2006). The role of the hypothalamic-pituitaryadrenal axis in neuroendocrine responses to stress. Dialogues Clin Neurosci 8: 383-395.

Smoak B, Deuster PA, Rabin D, Chrousos GP (1991). Corticotropinreleasing hormone is not the sole factor mediating exerciseinduced adrenocorticotropin release in humans. J Clin Endocrinol Metab. 73: 302-306. DOI: 10.1210/jcem-73-2-302.

Stephenson LA, Kolka MA, Francesconi R, Gonzalez RR (1989). Circadian variations in plasma renin activity, catecholamines and aldosterone during exercise in women. Eur J Appl Physiol Occup Physiol 58: 756-764. DOI: 10.1007/BF00637388.

Sundsfjord JA, Stromme SB, Aakvaag A (1975). Plasma aldosterone (PA), plasma renin activity (PRA) and cortisol (PC) during exercise. Metabolic Adaptation to Prolonged Physical Exercise 308-312.
Swain DP, Abernathy KS, Smith CS, Lee SJ, Bunn SA (1994). Target heart rates for the development of cardiorespiratory fitness. Med Sci Sports Exerc 26: 112-116. DOI: 10.1249/00005768199401000-00019.

Veldhuis JD, Iranmanesh A, Lizarralde G, Johnson ML (1989). Amplitude modulation of a burst like mode of cortisol secretion subserves the circadian glucocorticoid rhythm. Am J Physiol 257: 6-14. DOI: 10.1152/ajpendo.1989.257.1.E6.

Viru A (1985). Hormones in Muscular Activity. Hormonal Ensemble in Exercise, CRC Press, Inc.

Viru A, Smirnova T, Karelson K, Snegovskaya V, Viru M (1996). Determinants and modulators of hormonal responses to exercise. Biol Sport 13: 169-187.

Wideman L, Consitt L, Patrie J, Swearingin B, Bloomer R, Davis P, Weltman A (2006). The impact of sex and exercise duration on growth hormone secretion. J Appl Physiol 101: 1641-1647. DOI: 10.1152/japplphysiol.00518.2006.

Wideman L, Weltman JY, Story S, Veldhuis JD, Weltman A (1999). Effects of gender on exercise-induced growth hormone release. J Appl Physiol 87: 1154-1162. DOI: 10.1152/ jappl.1999.87.3.1154.

Wolf JP, Nguyen G, Berthelay S (1986). Plasma renin and aldosterone changes during twenty minutes' moderate exercise. Influence of posture. Eur J Appl Physiol Occup Physiol 54: 602-606. DOI: 10.1007/BF00943348.

Yamauchi T, Harada T, Kurono M, Matsui N (1998). Effect of exercise-induced acidosis on aldosterone secretion in men. Eur J Appl Physiol Occup Physiol 77: 409-412. DOI: 10.1007/ s004210050352. 